\title{
The microbiota in inflammatory bowel disease
}

\author{
Donal Sheehan $^{1,2} \cdot$ Carthage Moran $^{1,2} \cdot$ Fergus Shanahan $^{1,2}$
}

Received: 28 February 2015/Accepted: 1 March 2015/Published online: 26 March 2015

(C) Springer Japan 2015

\begin{abstract}
This review explores our current understanding of the complex interaction between environmental risk factors, genetic traits and the development of inflammatory bowel disease. The primacy of environmental risk factors is illustrated by the rapid increase in the incidence of the disease worldwide. We discuss how the gut microbiota is the proximate environmental risk factor for subsequent development of inflammatory bowel disease. The evolving fields of virome and mycobiome studies will further our understanding of the full potential of the gut microbiota in disease pathogenesis. Manipulating the gut microbiota is a promising therapeutic avenue.
\end{abstract}

Keywords Inflammatory bowel disease - Gut microbiota $\cdot$ Mycobiome $\cdot$ Virome $\cdot$ Faecal microbial transplantation

\section{Introduction}

The gut microbiota is altered in patients with inflammatory bowel disease (IBD). As the incidence of IBD rises worldwide [1] with socioeconomic development,

D. Sheehan and C. Moran contributed equally to this article.

Fergus Shanahan

f.shanahan@ucc.ie

Donal Sheehan

donalsheehan@me.com

1 Department of Medicine, University College Cork, National University of Ireland, Cork, Ireland

2 Alimentary Pharmabiotic Centre, University College Cork, National University of Ireland, Cork, Ireland environmental factors associated with modern life appear to be driving these microbial changes. Although genetic studies provide insight into disease mechanisms, the environmental influence on the microbiota may be the essential factor in disease development. The virome and mycobiome have been relatively neglected areas of research, but given their intricate interactions with the gut bacteria, future research in these fields will be important in understanding of the pathogenesis of IBD and its treatment.

\section{The gut microbiota: the proximate environmental risk factor for IBD}

The gut microbiota is the proximate environmental influence on the risk of IBD (Fig. 1), but it is unclear whether tissue damage results from an abnormal immune response to a normal microbiota or from a normal immune response against abnormal microbiota. The primacy of environmental risk factors in the development of IBD is demonstrated in twin studies. The concordance rate for ulcerative colitis (UC) is less than $20 \%$ and is around $50 \%$ for Crohn's disease (CD) in monozygotic twins [2-4]. Of note, twin studies have not provided much support for a host genetic influence on the gut microbiota [5]. Healthy siblings of patients with $\mathrm{CD}$ also display altered microbial and immune profiles associated with $\mathrm{CD}$, distinct from their genotype-related risk [6]. These findings suggest that although genes and the environment are important in disease development, the environment has a greater effect, especially in UC.

The increasing prevalence of IBD worldwide also supports the primacy of environmental risk factors $[7,8]$ in the development of IBD, except in rare cases of monogenic disease [9]. The most consistent epidemiological feature of 
Fig. 1 The gut microbiota is the proximate environmental influence on inflammatory bowel disease

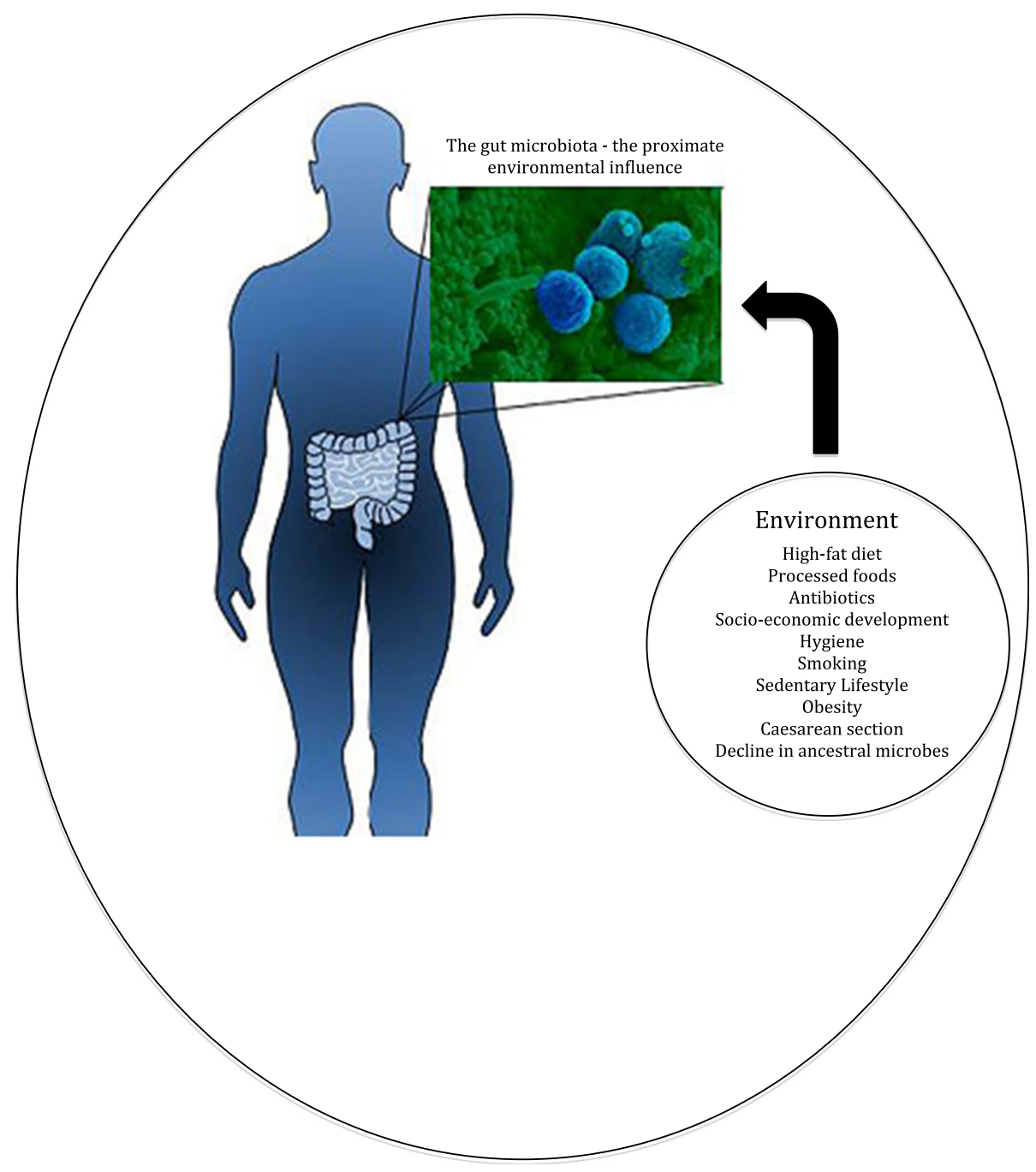

both UC and CD is the increase in incidence and prevalence when a society transitions from developing to developed [10]. The rapid pace of these epidemiological changes is too brisk for them to result from changes in gene frequency, pointing to an environmental effect on the risk of disease. Studies of emigrant groups support this hypothesis [7]. Studies of migrant populations suggest early childhood environmental influence is crucial; children take on the risk profile of their new environment, whereas their parents maintain the risk profile of their country of origin [11].

\section{Overlapping genetic and environmental risk factors for IBD}

Important environmental and lifestyle risk factors for the development of IBD include smoking [12], industrialization and socioeconomic development [13], oral contraceptive use [14] and diet [15].
Since the discovery of NOD2 [16, 17], more that 160 IBD-associated gene loci [18] have been identified. These genetic associations highlight the importance of gene-microbe-environment interactions in IBD pathogenesis. Key IBD risk gene pathways include sensing of the microbiota, regulators of the response to microbiota and barrier function (Table 1).

\section{Gene-environment interactions}

Environmental exposures in genetically susceptible individuals are believed to be a prime driver of IBD development. Smoking is a major environmental risk factor, with evidence for gene-microbe interactions in its contribution to disease. It has been independently demonstrated that $N o d 2^{-1-}$ mice have altered gut microbiota composition [29], and that cigarette smoke can alter NOD2 expression and function in intestinal epithelial cells [30].The polarizing effects of smoking on $\mathrm{CD}$ and $\mathrm{UC}$ emphasize the 
Table 1 Representative inflammatory bowel disease $(I B D)$ gene risk loci that regulate sensing of and response to the microbiota

\begin{tabular}{|c|c|c|}
\hline Genes & Comment & References \\
\hline NOD2 & CD-linked intracellular sensor of bacterial peptidoglycans & {$[16,17]$} \\
\hline ATG16L1, IRGM & $\mathrm{CD}$ risk autophagy genes involved in intracellular processing of bacteria & {$[19,20]$} \\
\hline$I L 23 R, J A K 2, I L 12 B$ & $\begin{array}{l}\text { IL-23- } \mathrm{T}_{\mathrm{h}} 17 \text { pathway linked to IBD and the autoimmune conditions psoriasis } \\
\text { and ankylosing spondylitis }\end{array}$ & {$[21]$} \\
\hline IL10 & Recessive mutations linked to very early onset IBD & [22] \\
\hline MUC19 & Involved in mucus production and mucosal barrier function & {$[23]$} \\
\hline SLC22A5, GPR35 & Immune response to bacterial-derived ligands and metabolites & {$[24]$} \\
\hline IL27 & Maintenance of epithelial barrier against commensal bacteria & {$[25]$} \\
\hline ECM1 & $\begin{array}{l}\text { Glycoprotein that interacts with the basement membrane, inhibits matrix metalloproteinase } \\
9 \text { and can activate NF- } \mathrm{kB} \text {. UC risk gene }\end{array}$ & {$[26]$} \\
\hline PTPN22 & $\mathrm{CD}$ risk gene with role in autoimmunity. Protective effect in UC & [27] \\
\hline$I K B L$ & MHC gene associated with severe UC & [28] \\
\hline
\end{tabular}

$C D$ Crohn's disease, $M H C$ major histocompatibility complex, $N F-\kappa B$ nuclear factor $\kappa \mathrm{B}, T_{h} 17$ type 17 helper $\mathrm{T}$ cell $U C$ ulcerative colitis

complexity of disease pathogenesis [31, 32]. In contrast to $\mathrm{CD}$, where smoking confers an elevated risk, smoking may suppress the risk of UC in genetically predisposed individuals until cessation of smoking. Unmasking of symptoms or precipitation of onset of UC may occur with removal of the potentially protective effect of smoking [33]. Another hypothesis is that smoking may influence disease phenotype at disease onset, resulting in the development of CD rather than UC in a proportion of smokers [33]. This may, in part, explain the apparent protective effect of smoking status on UC. In an intervention study, some patients with typical CD developed UC-like lesions of the distal colon after smoking cessation [34]. Smoking cessation is associated with an increase in abundance of Firmicutes and Actinobacteria and with a decrease in abundance of Bacteroidetes [35]. Microbial changes induced by smoking, along with other biological changes to mucosal homeostasis, may account for the variance of smoking as a risk factor for disease.

\section{Diet-microbe-gene interactions}

Diet is a major environmental risk factor that can directly influence gut microbial composition [36]. Population changes in dietary habits towards a processed diet with high fat and high sugar content is strongly linked to socioeconomic development, which itself has a strong epidemiological association with IBD. Several studies illustrate how dietary environmental insults resulting in compositional changes to the microbiota could theoretically lead to inflammation in genetically susceptible individuals. One report suggests that dietary-fat-induced taurocholic acid promotes the growth of the pathobiont Biophilia wadsworthia and induces colitis in $1110^{-1-}$ mice [37]. This has not been demonstrated in humans, but genetic defects in IL-10 and/or its receptor have been associated with IBD $[22,38]$.

Industrialized food processing and the use of food additives is a modern phenomenon. It has been shown that emulsifiers, commonly used food additives, can modulate the mouse gut microbiota, with resultant promotion of inflammation and metabolic syndrome [39]. Low concentrations of two commonly used emulsifiers, carboxymethylcellulose and polysorbate 80 , induced lowgrade inflammation and obesity in wild-type mice, and promoted colitis in genetically predisposed $\mathrm{IllO}^{-/-}$and $T l r 5^{-/-}$mice.

\section{Gene-gene interactions}

Many of the genetic loci that confer risk in IBD interact. The severity of disease phenotype may be determined by gene-gene interactions in the context of gene-microbe interactions. The direct interaction between NOD2 and autophagy genes is one example of this [40]. Activation of NOD2 by bacteria and bacterial ligands results in ATG16L1-mediated formation of autophagic vacuoles in epithelial and dendritic cells [41]. This microbial-stimulated autophagy induction is impaired in both NOD2 and $A T G 16 L 1$ variants associated with $\mathrm{CD}$. It appears that normal NOD2 function is necessary for recruitment of ATG16L1 to the plasma membrane at the site of bacterial entry and thus for the wrapping of invading bacteria by autophagosomes [40]. NOD2-dependent defects in bacterially induced autophagy responses have been demonstrated for adherent-invasive Escherichia coli bacteria, which are strongly associated with ileal $\mathrm{CD}$, and Salmonella typhius and Shigella, which are also linked to CD.

Another example of gene-gene interactions is the endoplasmic-reticulum-stress-induced unfolded protein 
pathway. The unfolded protein pathway genes $X B P 1$ and ORMDL3 have been associated with $\mathrm{CD}$ and $\mathrm{UC}$, and are closely linked to autophagy [42]. Autophagy appears to be a key converging pathway for the strongest genetic risk factors for IBD that result in inappropriate innate immune responses to the microbiota.

\section{Who becomes sick and the timing of onset}

The requirement for genes, microbes, a host and the environment in determining who becomes sick was elegantly shown in a study in which genetically susceptible mice became sick only in the presence of commensal bacteria, intact gut immunity and exposure to an environmental virus [43]. The co-occurrence of risk factors determines who becomes sick, but infections may determine the timing of disease onset. Disruption of the mucosal barrier by infectious or other environmental agents exposes the host immune system to the resident microbiota, leading to proliferation of pathogen-specific and commensal-specific $\mathrm{T}$ cells [44]. These cells migrate to other mucosal sites, where they react with the commensal microbiota and can tip the balance from physiologic to pathologic inflammation. As the common mucosal immune system enables lymphocytes to migrate among different mucosal tissues, it is possible that commensal-specific $\mathrm{T}$ cells generated by infection at an extraintestinal site might migrate to the intestine. This might account for some patients developing relapses of IBD with concurrent infections.

\section{The changing phenotype of IBD}

The phenotype of patients with IBD has changed in recent decades (Table 2), and the microbiota may have contributed to this. There have been changes in disease behaviour, risk of surgery and nutritional status. There have also been changes in the incidence of IBD amongst different ethnic groups as they are exposed to increasingly industrialized environments [8].

Disease phenotype at diagnosis of IBD has changed over recent decades. A Danish study investigating consecutive population-based cohorts describes these changes. The proportion of $\mathrm{CD}$ patients amongst the total IBD cohort increased and the prevalence of $\mathrm{CD}$ and UC patients who were smokers at diagnosis decreased with time. The median age at diagnosis was stable over five decades for CD patients, but increased from 34 to 38 years in patients with UC [45].

A Dutch population study of patients with newly diagnosed IBD in 2006 found $61 \%$ of patients with CD had ileal involvement, $31 \%$ of patients had stricturing or penetrating disease and in $4 \%$ of patients there was upper gastrointestinal tract involvement at diagnosis [54]. For CD patients, the mean age at diagnosis was 36.7 years. In the Olmsted County cohort study (1970-2004), $81.4 \%$ of patients had non-stricturing, non-penetrating disease at diagnosis; $64 \%$ had ileal involvement at diagnosis [55]. The phenotype at diagnosis in patients with UC is generally split equally among proctitis, left-sided disease and pancolitis $[56,57]$. The proportion of patients presenting with pancolitis increased over the five decades in Denmark [45]. IBD in patients with primary sclerosing cholangitis is a distinct phenotype, with such patients having increased risk of pouchitis (not related to the severity of liver disease) [58] and colorectal cancer, in addition to risks of cholangiocarcinoma, liver failure and gallbladder cancer.

The phenotype of disease amongst Asian patients with IBD can differ from that of patients from western Europe and North America [59]. Male predominance [57] of increased ileocolonic disease has been described amongst Asian cohorts of patients with CD. However, a recent study failed to show a significant difference in disease location between Asian and Australian cohorts [57].

Twin studies have shown that phenotype is an important factor in determining changes in gut microbiota [5]. Ileal CD patients were found to have lower abundance of Firmicutes compared with healthy controls, whereas colonic CD patients had increased abundance [5]. Conversely, the abundance of Fusobacteria was increased in ileal CD patients and decreased in colonic CD patients compared with healthy controls [5]. An increase in abundance of Proteobacteria was reported in ileal $\mathrm{CD}$ patients compared with healthy controls, but this finding was not observed between healthy controls and colonic CD patients [5]. Disease phenotype appears to outweigh the effects of genotype on the microbiome, although studies in twins do not differentiate early environmental influences on the microbiota that persist from genetic influences [60]. A large study of paediatric patients with treatment-naïve IBD found the presence of deep ulcers on endoscopy was associated with increased abundance of Pasteurellacaea, Veillonellacea and Rothia mucilaginosa [61]. Disease location (colonic, ileocolonic and ileal) did not significantly disrupt the similarity between rectal- and ileal-biopsy-associated microbiome profiles [61].

Obesity has reached epidemic proportions in Western countries, becoming an equal if not greater contributor to burden of disease than smoking in the USA [62]. Regression in life expectancy in the twenty-first century is predicted if the rate of obesity remains unchecked [63]. Malnutrition has long been recognized as a complication of IBD. Previously, attention focused on patients who were underweight, but obesity is increasingly associated with IBD [47]. 
Table 2 The changing phenotype of patients with inflammatory bowel disease (IBD)

\begin{tabular}{|c|c|c|}
\hline Feature & Comment & References \\
\hline \multirow[t]{4}{*}{ Increased BMI } & $\begin{array}{l}\text { Prevalence of obese and overweight patients in a Scottish IBD population was } 18 \text { and } 38 \% \text {, } \\
\text { respectively }\end{array}$ & [46] \\
\hline & $17 \%$ of patients with CD in an Irish cohort were obese compared with $12 \%$ of controls & [47] \\
\hline & Increased weight of patients with CD enrolling in clinical trials (1991-2008) & [48] \\
\hline & $23 \%$ of paediatric patients with IBD in the USA were found to be overweight or obese & [49] \\
\hline \multirow[t]{2}{*}{ Decreased rate of surgery } & $\begin{array}{l}\text { Cumulative probability of first major surgery at } 9 \text { years decreased from } 50 \%(1979-1986) \text { to } 23 \% \\
(2003-2011) \text { in patients with CD, and from } 14 \text { to } 9 \% \text { in patients with UC }\end{array}$ & {$[50]$} \\
\hline & $\begin{array}{l}\text { Decreased risk of surgery in patients in whom CD was diagnosed after 1996, associated with } \\
\text { increased specialist care }\end{array}$ & {$[51]$} \\
\hline \multirow{2}{*}{$\begin{array}{l}\text { Increasing prevalence of } \\
\text { elderly-onset IBD }\end{array}$} & Increased proportion of colonic disease and inflammatory behaviour in elderly patients with CD & {$[52,53]$} \\
\hline & Progression of disease behaviour less than in younger patients. Milder disease course & {$[52]$} \\
\hline
\end{tabular}

$B M I$ body mass index, $C D$ Crohn's disease, $U C$ ulcerative colitis

Data from a northern European population reported that the prevalence of obese and overweight patients in an IBD population was 18 and $38 \%$, respectively [46]. In the overweight/obese cohort of UC patients there were higher levels of surgery, but the converse was true for the $\mathrm{CD}$ cohort. In that study there were significantly more obese patients with CD than with UC [46]. There has been an increase in weight and disease activity in patients with $\mathrm{CD}$ enrolling in clinical trials in the last 20 years [48].

A large prospective study found no association between obesity and development of incident IBD [64]. This cohort had a predominance of middle-aged subjects, the median age being approximately 53 years. IBD tends to occur at an earlier age. Conversely, a recent case-control study investigated a cohort of patients aged 50-70 years, finding obesity was commoner in patients with $\mathrm{CD}$ than in community controls without IBD [65]. A subsequent study of American women found that obese women were at increased risk of developing CD [66].

Earlier paediatric IBD populations have been described as being underweight and malnourished, with lower body mass index (BMI) than the normal distribution [67]. However, studies since the turn of the millennium have revealed that children with IBD are affected by current population trends towards weight gain; $10 \%$ and $20-30 \%$ of incident $\mathrm{CD}$ and UC patients were overweight or at risk of being overweight as per BMI [68]. These studies also showed that $22-24 \%$ and $7-9 \%$ of incident CD and UC patients had low BMI.

A large, multicentre cohort study of children $(1,598)$ with IBD was performed in the USA, where childhood obesity has become epidemic; $31.7 \%$ of children are estimated to be overweight or obese [69]. The overall prevalence of overweight or obesity in this IBD population was $23.4 \%$, with 20 and $30.1 \%$ of the $\mathrm{CD}$ and UC population overweight or obese, respectively [49]. Paediatric patients with $\mathrm{CD}$ who are overweight or obese were found to have higher rates of IBD-related surgery, which is similar to findings in adult populations [70]. Corticosteroid use was associated with the overweight/obese UC group (35\% vs $27 \%$ ) but not the CD group.

The rise of obesity is especially concerning in patients with IBD as it a known risk factor for colorectal cancer (CRC) [71], and can affect the efficacy of medical treatment [72]. We have previously reviewed the role of the gut microbiota in obesity [73]. Similarly to IBD, obesity is an increasing health issue worldwide, with dietary, environmental and genetic factors important in the development of obesity. Early exposure to antibiotics in mice alters their microbiota, leading to lasting effects on body composition [74]. Exposure to antibiotics in the first years of life is associated with early-childhood obesity [75]. Onset of IBD during childhood is also associated with antibiotic use in the first year of life [76]. A metagenomic systems biology computational framework identified both network-level and gene-level topological differences associated with IBD and obesity [77]. These "Western" diseases are increasing in prevalence, and manipulating the gut microbiota is an attractive therapeutic approach in their management. Strategies for combating obesity and related conditions that involve manipulating the gut microbiota include bariatric surgery [78, 79], microbial transplantation [80, 81] and probiotics [82].

\section{Microbiota studies in patients with IBD}

Studies profiling the gut microbiota in patients with IBD compared with controls have consistently shown changes in microbiota composition as well as reduction in overall biodiversity [83] (Fig. 2, Table 3). The largest study to date in a treatment-naïve cohort of paediatric patients with CD [61], in whom analysis of mucusol and lumen-associated microbiota was performed, confirms that inflammation 
Fig. 2 Major findings from microbial studies of patients with inflammatory bowel disease

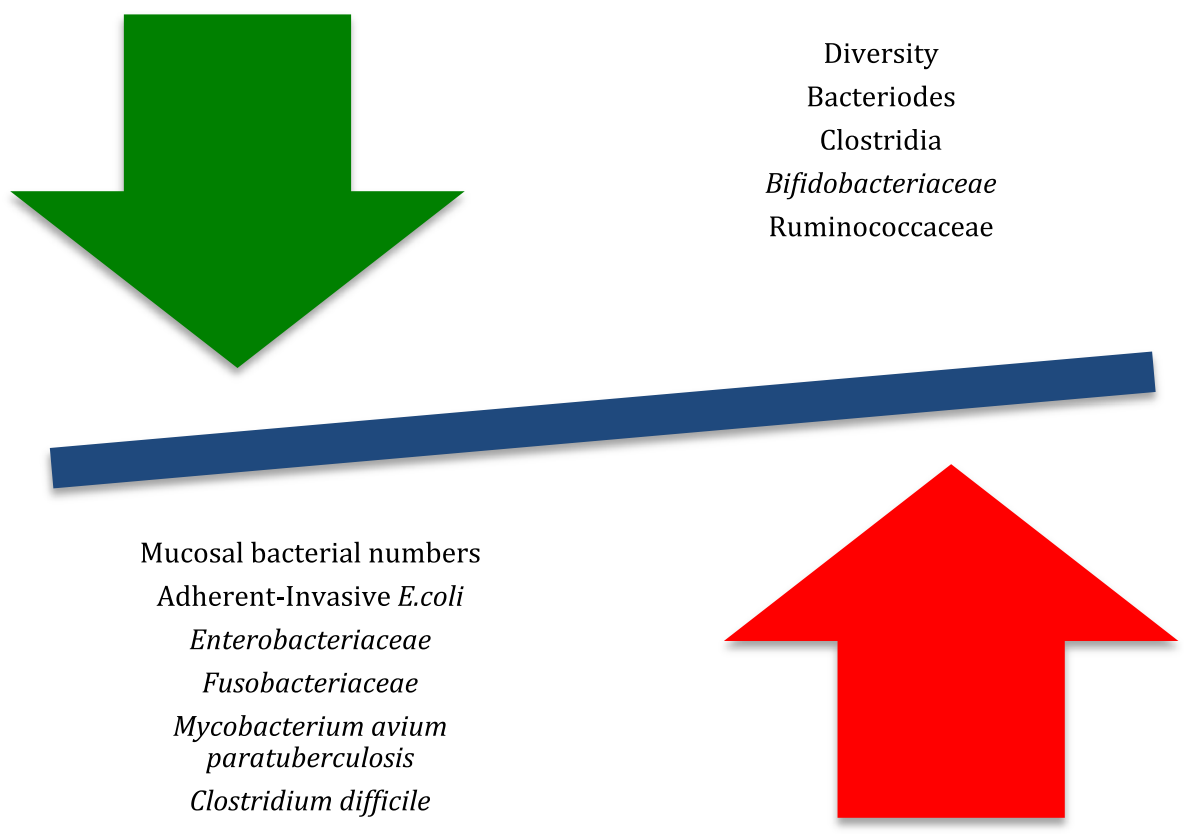

Table 3 Microbiota in inflammatory bowel disease (IBD)

\begin{tabular}{|c|c|c|}
\hline Bacteria & Comment & References \\
\hline Adherent-invasive Escherichia coli & Abundance increased in ileal CD & {$[84]$} \\
\hline Fusobacterium & Associated with $\mathrm{CD}, \mathrm{UC}$ and $\mathrm{CRC}$ & {$[61,93,94]$} \\
\hline Faecalibacterum prausnitizi & $\begin{array}{l}\text { Abundance of this butyrate-producing member of the family Ruminococcaceae } \\
\text { reduced in ileal CD }\end{array}$ & {$[101]$} \\
\hline Roseburia & $\begin{array}{l}\text { Clade XIVa Clostridia, associated with anti-inflammatory } \mathrm{T} \text { cell production. } \\
\text { Abundance reduced in CD and UC }\end{array}$ & {$[88]$} \\
\hline Odoribacter & $\begin{array}{l}\text { Phylum Bacteriodes. SCFA producer. Abundance reduced in pancolonic UC and } \\
\text { ileal CD }\end{array}$ & {$[88]$} \\
\hline Bifidobacterium & Abundance decreased in $\mathrm{CD}$ & {$[61]$} \\
\hline Anaerostipes & $\begin{array}{l}\text { Phylum Firmucutes. Butyrate producer. Abundance decreased in current or } \\
\text { former smokers }\end{array}$ & {$[88]$} \\
\hline $\begin{array}{l}\text { Mycobacterium avium subsp. } \\
\text { paratuberculosis. }\end{array}$ & Linked to CD & {$[105]$} \\
\hline Clostridium difficile & IBD patients have increased risk of colonization and infection & {$[106]$} \\
\hline
\end{tabular}

$C D$ Crohn's disease, $C R C$ colorectal cancer, $S C F A$ short-chain fatty acid, $U C$ ulcerative colitis

is strongly associated with an overall drop in species diversity and alterations in the abundance of several taxa. The disease state was associated with increased abundance of Enterobacteriaceae, Fusobacteriaceae, Pasteurellaceae, and Bifidobacteriaceae.Significantly, the imbalance in microbiota compostion described was observed only in the analysis performed on tissue samples; much weaker associations were described in stool sample analysis, suggesting less dramatic shifts in the luminal microbiota despite a disease state [61]. Microbiota profiles at diagnosis predicted follow-up clinical outcomes as measured by the paediatric CD activity index: the levels of Enterobacteriaceae were negatively correlated with future paediatric CD activity index and the levels of Fusobacterium and Haemophlius were positively correlated.

Significant research interest has focused on the role of E. coli particularly in patients with ileal CD [84], with studies consistently demonstrating increased levels of mucosa-associated E. coli. A new pathogen strain with adherent and invasive behaviours termed "adherent-invasive E. coli" has been isolated from ileal biopsy samples of patients with CD [85]. Adherent-invasive E. coli bacteria have the ability to invade epithelial cells and replicate within macrophages [86]. Although they can be present in healthy individuals, it has been shown that they are unable to adhere to ileal enterocytes isolated from healthy 
individuals [87]. This suggests the inflamed ileum provides a niche environment for these pathobionts, which may influence disease exacerbations and chronicity. The genera Escherichia and Shigella have been found to be highly enriched in ileal CD [88]. E. coli bacteria produce lipopolysaccharide, which can trigger the inflammatory cascade via Toll-like receptor 4 signalling [89]. Mutations in the TLR4 gene are associated with CD and UC [90], and $T L R 4$ expression is upregulated in intestinal epithelium of IBD patients [91]. It has also been demostrated that mesalamine use is linked to a strong reduction in the abundance of Echerichia and Shigella [88, 92].

Increased abundance of Fusobacteria, another phylum of adherent and invasive bacteria, has been associated with both UC and CD [93]. Fusubacterium species have also been linked to CRC [94]. They are enriched in tumour tissue compared with adjacent normal colon in patients with CRC, in adenomas compared with normal tissue, and in stool samples from patients with both adenomas and adenocarcinomas [95]. Possible mechanisms of action in stimulation of growth of $\mathrm{CRC}$ relate to the ability of $\mathrm{Fu}$ sobacterium to invade and induce oncogenic and inflammatory responses through its unique FadA adhesin, which binds to E-cadherin and activates $\beta$-catenin signalling [96]. Potential mechanisms of function of Fusobacterium in IBD have not been described, but the invasive ability of $\mathrm{Fu}$ sobacterium has been positively correlated with the IBD status of the host [97]. Fusobacterium provides a potential theoretical link given the increased risk of CRC associated with IBD.

The depletion of certain bacteria and loss of their protective functions are likely to have a significant impact on disease course. Many of the protective functions of the bacteria linked to IBD relate to their ability to ferment dietary fibre to produce short-chain fatty acids (SCFA) [98]. SFCA are a key source of energy for colonic epithelial cells [99], and regulate colonic regulatory $\mathrm{T}$ cell homeostasis [100]. In ileal CD, the abundance of members of the family Ruminococcaceae, in particular Faecalibacterium, is reduced [88, 101]. Faecalibacterium prausnitizi is a major producer of the SCFA butyrate, exhibits antiinflammatory effects in a colitis setting [102] and provides the first step in microbiome-linked carbohydrate metabolism by degrading dietary polysaccharides [103]. Reductions in the abundance of $F$. prausnitizi have been associated with higher risk of postoperative recurrence of ileal CD [102], and administration of $F$. prausnitizi reduces inflammation in mouse models [102]. Roseburia, the abundance of which is reduced in all IBD subgroups [88], is connected to the family Ruminococcaceae as it relies on its members to produce acetate, which it uses to produce butyrate [104]. The abundance of Odoribacter splanchus, another SCFA producer, is reduced in patients with pancolitis and in patients with ileal CD [88]. All the abovedescribed changes in bacterial populations have plausible functional consequences for the ability of the host to regulate inflammation mediated in part by the effect on SCFA production.

Metagenomic studies have identified functional microbiome pertubations in IBD [88]. Metagenomic analysis is important as the functional composition of the microbiota exhibits more stability than the microbiota at the phylogenetic level over time and between individuals [83]. One study identified only nine bacterial clades associated with UC patients compared with controls, but 21 differences in functional and metabolic pathways, with similar findings for CD patients [88]. Changes seen in both UC and CD include decreased expression of genes involved in amino acid metabolism and synthesis, and increased expression of genes related to sulfate transport as well as genes involved in glutathione transport. Glutathione is significant as it is produced by Proteobacteria and enteroccocci, and is involved in the maintenance of bacterial homeostasis during oxidative stress. Ileal CD is associated with specific alterations in microbiota gene expression, including increase in expression of genes involved in glycolysis and carbohydrate metabolism and reduction in expression of genes involved in lipid metabolism, indicating alterations in energy metabolism. Increased expression of adherance-invasion and type 2 secretion system genes that are involved in pathologic processes typical of pathobionts is also seen. Expression of these genes results in tissue destruction and forms part of a cycle of inflammation [88].

\section{The gut virome and IBD}

Human microbiota studies to date have focused on bacteria, generally neglecting the non-bacterial components of the gut microbiota. Viruses, which include phages, in fact compromise the most abundant biological entities within the gut, greatly outnumbering bacteria, with an estimated total of $10^{15}$ [107]. The function of viruses in the healthy gut and in gastrointestinal disease is not well defined; however, a number of studies suggest an important role. It has been demonstrated that a common enteric RNA virus can replace the beneficial function of commensal bacteria in the intestine [108]. In that study, infection of germ-free or antibiotic-treated mice with murine norovirus (MNV) restored intestinal morphology and lymphocyte function without inducing overt inflammation. MNV infection was also shown to offset the deleterious effect of treatment with antibiotics in models of intestinal injury and pathogenic bacterial infection. This study supports the hypothesis that similarly to bacteria, eukaryotic viruses have the capacity to support intestinal homeostasis and shape mucosal 
immunity. As mentioned in mouse models of the Atg16L1 gene, a CD susceptibility gene involved in autophagy, hypomorphic ATG16L1 disrupts Paneth cell function [109]; intriguingly, this is dependant on the environmental contribution of MNV infection [43].

Given their biological characteristics, in particular their influence on bacterial populations, there is emerging interest in the potential role of phages in IBD. Phages are bacterial viruses that can attack and kill a target bacterium [110]. They bind to specific targets on the bacterial cell surface, so individual phages generally target a very narrow range of strains of the same bacterial species. Phages shape microbial population structure [111] and maintain microbial diversity within the gut by restricting the clonal expansion of microbes that respond most efficiently to external stimuli. They do this by reacting in a 'kill the winner' dynamic referred to as the constant diversity model [112]. Several studies have already looked at phages in IBD. In mucosa biopsy samples, phage numbers were significantly higher in patients with CD than in controls [113]. Phage populations are more diverse in patients with $\mathrm{CD}$ than in healthy individuals, and there is interindividual variation in phage diversity in patients with CD [114]. The possibility of using phages as viral biomarkers has potential. One study found among the viral biomarkers identified, $5 \%$ were more represented in $\mathrm{CD}$ patients than in healthy controls [115]. A recent publication confirms increased richness and biodiversity of phage populations in IBD patients compared with controls [116]. Specifically, increases in the abundance of Claudovirales in IBD patients were seen. Disease-specific changes to the virome in $\mathrm{CD}$ and UC were also described. The increased biodiversity of phage populations was in contrast to the expected reduced bacterial biodiversity, again described in IBD patients. Phage populations also respond to environmental factors, such as diet [117] and antibiotic exposure [118], known IBD risk factors.

\section{The mycobiome and IBD}

The mycobiome is another relatively unexplored area of research [119]. The fungal components of the gastrointestinal tract have been characterized in healthy individuals [120]. The gastrointestinal tract was found to contain Aspergillus, Cryptococcus, Penicillium, Pneumocystis and Saccharomycetaceae yeasts (Candida and Saccharomyces). Fungal abundance has also been correlated with consumption of a diet rich in carbohydrates [121]. Candida was positively correlated with carbohydrate consumption and negatively correlated with total saturated fatty acid levels. Aspergillus was negatively correlated with SCFA levels in people ingesting a carbohydrate-rich diet. In addition, significant correlations between fungal and bacterial taxa have been described. Interactions between fungi and bacteria in the gastrointestinal tract, as well as with dietary components, are potentially relevant to IBD. A study in IBD patients revealed higher fungal diversity in patients with $\mathrm{CD}$ in comparison with controls, and no disease-specific fungal species were found in the $\mathrm{CD}$ and UC groups [122].

\section{Therapeutic manipulation}

Current approaches used in the therapeutic manipulation of the gut microbiota include antibiotics, probiotics and prebiotics or combinations thereof (synbiotics). Faecal microbiota transplantation (FMT) has garnered much interest as a treatment for IBD, especially UC.

Antibiotics may have a role in inducing remission in active disease and preventing relapse in some patients with IBD. Their use though is generally restricted to colonic disease [123] and complications of CD [123]. Metronidazole, in combination with azathioprine, has also shown efficacy in reducing postoperative occurrence of CD [124]. A meta-analysis of antibiotic therapy in IBD found that antibiotics significantly improved outcomes [125]. However, this analysis included patients who were treated with a diverse number of antibiotics. There was also heterogeneity amongst the trials studied, making interpretation difficult. Further clinical trials will enhance our understanding of the clinical situations whereby antibiotics may be effective, and hopefully these trials will study changes that occur in the gut microbiota.

When considering using probiotics in clinical practice, one must understand that all probiotics are not equal, and their effectiveness depends on the strain, dosage and clinical condition that is the target for therapy [126]. The use of probiotics has been reviewed extensively elsewhere, but it should be noted that as IBD is a heterogeneous condition, one would expect different probiotics to be effective for different manifestations of the disease.

\section{Faecal microbiota transplantation}

FMT is a highly successful treatment for severe and recurrent Clostridium difficile infection, prompting further interest in its potential in IBD [127]. Several studies have been published on the use of FMT in IBD [128]. In one study, FMT was administered via enema in a small group of children and young adults [129], and no serious adverse events were reported. A further study, in which five patients with moderate to severe active UC received FMT via nasojejenul tube and enema [130], found that FMT elicited 
fever and transient rises in the level of C-reactive protein. One patient in this study had a positive clinical response after 12 weeks. These studies provide limited information regarding the potential clinical benefit of FMT. Clearly, further studies are needed; several studies are registered at ClinicalTrials.gov, and the results of these are awaited.

Although FMT proved safe [131], it does give rise to novel safety concerns. Transmission of known pathogens should be avoidable with appropriate screening, but questions remain regarding the risk posed by undiscovered pathogens. The potential for inducing bacterial translocation and sepsis particularly in patients with defective mucosal barrier function is also a major concern. More theoretical is the risk of transferring an undesirable phenotype, given the numerous gut microbial associations with diseases, including colon cancer [94]. Experimental models and human studies [81] have shown that immunologic, physiologic and metabolic phenotypes can be transferred by FMT [126]. The potential for a negative phenotype transfer is particularly relevant to IBD, where recipients of FMT are likely to be young, with an added risk of carcinogenesis. Optimal donor selection is a key safety priority; donor selection needs to be refined, with greater attention on phenotype and composition and diversity of donor microbiota.

Enthusiasm for FMT in IBD is tempered by unique challenges that also offer opportunities for discovery. Host-microbe interactions in IBD are more complex than in C. difficile-associated diarrhoea or Helicobacter-related peptic ulcer disease. Thus, the traditional 'one microbeone disease' model makes way in IBD for the idea that groups of commensals may become pathogenic in certain contexts depending on host susceptibility. The role of the microbiota in IBD may vary at different phases in the evolution of the disease. The optimal time for microbial manipulation may be in early life, when immune development is occurring in concert with gut colonization. Patients with established IBD may, in fact, have missed the window of opportunity [132]. UC and CD are heterogeneous disorders, suggesting that microbial-based strategies may require the identification of responder subgroups. This highlights the need for microbial and other biomarkers of disease subsets. Further unknowns surround the optimum composition of the donor stool and whether it should be matched to the recipient's genotype and phenotype.

Faecal biotherapy for IBD is currently a discipline in its infancy, and future developments are likely to see the use of more sophisticated and targeted approaches that use defined microbial ecosystems with precise mixtures of the minimal microbes from stool needed to achieve specific benefits [132]. Such an approach has already been successfully used in the RePOOPulate study [133], where a selected microbial ecosystem of 33 bacteria from a single donor was used to treat $C$. difficile infection in two patients. Technologies using minimal microbiota mixtures have considerable potential advantages, such as avoiding the need for repeated stool donation, reducing the chance of the transfer of infection and allowing uniformity in the treatment given to patients. They also mark the move towards the development of a new class of therapeutics derived from the gut microbiota, with mechanism-based synthetic microbiota communities being designed to target disease-specific microbial compositional and functional imbalances.

\section{Conclusion}

If the last decade was the decade for genetics in IBD, the present is the decade of the microbiome. The next decade will focus on gene-microbe interactions and translation to the clinic.

Acknowledgment The authors are supported, in part, by Science Foundation Ireland in the form of a centre grant (Alimentary Pharmabiotic Centre: grants SFI/12/RC/2273 and 12/RC/2273).

Conflict of interest The authors declare that they have no conflict of interest.

\section{References}

1. Molodecky NA, Soon IS, Rabi DM, et al. Increasing incidence and prevalence of the inflammatory bowel diseases with time, based on systematic review. Gastroenterology. 2012;142:46-54.

2. Brant SR. Update on the heritability of inflammatory bowel disease: the importance of twin studies. Inflamm Bowel Dis. 2011;17:1-5.

3. Spehlmann ME, Begun AZ, Burghardt J, et al. Epidemiology of inflammatory bowel disease in a German twin cohort: results of a nationwide study. Inflamm Bowel Dis. 2008;14:968-76.

4. Halfvarson J, Bodin L, Tysk C, et al. Inflammatory bowel disease in a Swedish twin cohort: a long-term follow-up of concordance and clinical characteristics. Gastroenterology. 2003; 124:1767-73.

5. Willing BP, Dicksved J, Halfvarson J, et al. A pyrosequencing study in twins shows that gastrointestinal microbial profiles vary with inflammatory bowel disease phenotypes. Gastroenterology. 2010;139(6):1844-54.e1.

6. Hedin CR, McCarthy NE, Louis P, et al. Altered intestinal microbiota and blood $\mathrm{T}$ cell phenotype are shared by patients with Crohn's disease and their unaffected siblings. Gut. 2014; 63:1578-86.

7. Barreiro-de Acosta M, Alvarez Castro A, Souto R, et al. Emigration to western industrialized countries: a risk factor for developing inflammatory bowel disease. J Crohns Colitis. 2011;5: 566-9.

8. Cosnes J, Gower-Rousseau C, Seksik P, et al. Epidemiology and natural history of inflammatory bowel diseases. Gastroenterology. 2011;140:1785-94. 
9. Uhlig HH. Monogenic diseases associated with intestinal inflammation: implications for the understanding of inflammatory bowel disease. Gut. 2013;62:1795-805.

10. Bernstein CN, Shanahan F. Disorders of a modern lifestyle: reconciling the epidemiology of inflammatory bowel diseases. Gut. 2008;57:1185-91.

11. Probert CS, Jayanthi V, Pinder D, et al. Epidemiological study of ulcerative proctocolitis in Indian migrants and the indigenous population of Leicestershire. Gut. 1992;33:687-93.

12. Higuchi LM, Khalili H, Chan AT, et al. A prospective study of cigarette smoking and the risk of inflammatory bowel disease in women. Am J Gastroenterol. 2012;107:1399-406.

13. Ng SC, Bernstein CN, Vatn MH, et al. Geographical variability and environmental risk factors in inflammatory bowel disease. Gut. 2013;62:630-49.

14. Cornish JA, Tan E, Simillis C, et al. The risk of oral contraceptives in the etiology of inflammatory bowel disease: a metaanalysis. Am J Gastroenterol. 2008;103:2394-400.

15. Bernstein CN, Loftus EV Jr, Ng SC, et al. Hospitalisations and surgery in Crohn's disease. Gut. 2012;61:622-9.

16. Ogura $\mathrm{Y}$, Bonen DK, Inohara N, et al. A frameshift mutation in NOD2 associated with susceptibility to Crohn's disease. Nature. 2001;411:603-6.

17. Hugot JP, Chamaillard M, Zouali H, et al. Association of NOD2 leucine-rich repeat variants with susceptibility to Crohn's disease. Nature. 2001;411:599-603.

18. Knights D, Lassen KG, Xavier RJ. Advances in inflammatory bowel disease pathogenesis: linking host genetics and the microbiome. Gut. 2013;62:1505-10.

19. Hampe J, Franke A, Rosenstiel P, et al. A genome-wide association scan of nonsynonymous SNPs identifies a susceptibility variant for Crohn disease in ATG16L1. Nat Genet. 2007;39: 207-11.

20. Parkes M, Barrett JC, Prescott NJ, et al. Sequence variants in the autophagy gene IRGM and multiple other replicating loci contribute to Crohn's disease susceptibility. Nat Genet. 2007;39: $830-2$.

21. Abraham $\mathrm{C}$, Cho JH. Inflammatory bowel disease. $\mathrm{N}$ Engl $\mathrm{J}$ Med. 2009;361:2066-78.

22. Glocker EO, Kotlarz D, Boztug K, et al. Inflammatory bowel disease and mutations affecting the interleukin-10 receptor. N Engl J Med. 2009;361:2033-45.

23. Kumar V, Mack DR, Marcil V, et al. Genome-wide association study signal at the 12q12 locus for Crohn's disease may represent associations with the MUC19 gene. Inflamm Bowel Dis. 2013;19:1254-9.

24. Leung E, Hong J, Fraser AG, et al. Polymorphisms in the organic cation transporter genes SLC22A4 and SLC22A5 and Crohn's disease in a New Zealand Caucasian cohort. Immunol Cell Biol. 2006;84:233-6.

25. Jostins L, Ripke S, Weersma RK, et al. Host-microbe interactions have shaped the genetic architecture of inflammatory bowel disease. Nature. 2012;491:119-24.

26. Fisher SA, Tremelling M, Anderson CA, et al. Genetic determinants of ulcerative colitis include the ECM1 locus and five loci implicated in Crohn's disease. Nat Genet. 2008;40: $710-2$.

27. Diaz-Gallo LM, Espino-Paisan L, Fransen K, Gomez-Garcia M, van Sommeren S, Cardena C, et al. Differential association of two PTPN22 coding variants with Crohn's disease and ulcerative colitis. Inflamm Bowel Dis. 2011;17:2287-94.

28. de la Concha EG, Fernandez-Arquero M, Lopez-Nava G, et al. Susceptibility to severe ulcerative colitis is associated with polymorphism in the central MHC gene IKBL. Gastroenterology. 2000;119:1491-5.
29. Mondot S, Barreau F, Al Nabhani Z, et al. Altered gut microbiota composition in immune-impaired $\mathrm{Nod}^{-/-}$mice. Gut. 2012;61:634-5.

30. Aldhous MC, Soo K, Stark LA, et al. Cigarette smoke extract (CSE) delays NOD2 expression and affects NOD2/RIPK2 interactions in intestinal epithelial cells. PLoS One. 2011;6:e24715.

31. Cosnes J. Tobacco and IBD: relevance in the understanding of disease mechanisms and clinical practice. Best Pract Res Clin Gastroenterol. 2004;18:481-96.

32. Birrenbach T, Bocker U. Inflammatory bowel disease and smoking: a review of epidemiology, pathophysiology, and therapeutic implications. Inflamm Bowel Dis. 2004;10:848-59.

33. Abraham N, Selby W, Lazarus R, et al. Is smoking an indirect risk factor for the development of ulcerative colitis? An age- and sex-matched case-control study. J Gastroenterol Hepatol. 2003;18:139-46.

34. Cosnes J, Beaugerie L, Carbonnel F, et al. Smoking cessation and the course of Crohn's disease: an intervention study. Gastroenterology. 2001;120:1093-9.

35. Biedermann L, Brulisauer K, Zeitz J, et al. Smoking cessation alters intestinal microbiota: insights from quantitative investigations on human fecal samples using FISH. Inflamm Bowel Dis. 2014;20:1496-501.

36. Claesson MJ, Jeffery IB, Conde S, et al. Gut microbiota composition correlates with diet and health in the elderly. Nature. 2012;488:178-84.

37. Devkota S, Wang Y, Musch MW, et al. Dietary-fat-induced taurocholic acid promotes pathobiont expansion and colitis in $1110^{-1-}$ mice. Nature. 2012;487:104-8.

38. Franke A, Balschun T, Karlsen TH, et al. Sequence variants in IL10, ARPC2 and multiple other loci contribute to ulcerative colitis susceptibility. Nat Genet. 2008;40:1319-23.

39. Chassaing B, Koren O, Goodrich JK, et al. Dietary emulsifiers impact the mouse gut microbiota promoting colitis and metabolic syndrome. Nature. 2015. doi:10.1038/nature14232.

40. Travassos LH, Carneiro LA, Ramjeet M, et al. Nod1 and Nod2 direct autophagy by recruiting ATG16L1 to the plasma membrane at the site of bacterial entry. Nat Immunol. 2010;11: $55-62$.

41. Cooney R, Baker J, Brain O, et al. NOD2 stimulation induces autophagy in dendritic cells influencing bacterial handling and antigen presentation. Nat Med. 2010;16:90-7.

42. Kaser A, Blumberg RS. Endoplasmic reticulum stress and intestinal inflammation. Mucosal Immunol. 2010;3:11-6.

43. Cadwell K, Patel KK, Maloney NS, et al. Virus-plus-susceptibility gene interaction determines Crohn's disease gene Atg16L1 phenotypes in intestine. Cell. 2010;141:1135-45.

44. Hand TW, Dos Santos LM, Bouladoux N, et al. Acute gastrointestinal infection induces long-lived microbiota-specific $\mathrm{T}$ cell responses. Science. 2012;337:1553-6.

45. Jess T, Riis L, Vind I, et al. Changes in clinical characteristics, course, and prognosis of inflammatory bowel disease during the last 5 decades: a population-based study from Copenhagen. Den Inflamm Bowel Dis. 2007;13:481-9.

46. Steed H, Walsh S, Reynolds N. A brief report of the epidemiology of obesity in the inflammatory bowel disease population of Tayside. Scotl Obes Facts. 2009;2:370-2.

47. Nic Suibhne T, Raftery TC, McMahon O, et al. High prevalence of overweight and obesity in adults with Crohn's disease: associations with disease and lifestyle factors. J Crohns Colitis. 2013; 7:e241-8.

48. Moran GW, Dubeau MF, Kaplan GG, et al. The increasing weight of Crohn's disease subjects in clinical trials: a hypothesis-generatings time-trend analysis. Inflamm Bowel Dis. 2013;19:2949-56. 
49. Long MD, Crandall WV, Leibowitz IH, et al. Prevalence and epidemiology of overweight and obesity in children with inflammatory bowel disease. Inflamm Bowel Dis. 2011;17: 2162-8.

50. Rungoe C, Langholz E, Andersson M, et al. Changes in medical treatment and surgery rates in inflammatory bowel disease: a nationwide cohort study 1979-2011. Gut. 2014;63:1607-16.

51. Nguyen GC, Nugent Z, Shaw S, et al. Outcomes of patients with Crohn's disease improved from 1988 to 2008 and were associated with increased specialist care. Gastroenterology. 2011;141: 90-7.

52. Charpentier C, Salleron J, Savoye G, et al. Natural history of elderly-onset inflammatory bowel disease: a population-based cohort study. Gut. 2014;63:423-32.

53. Juneja M, Baidoo L, Schwartz MB, et al. Geriatric inflammatory bowel disease: phenotypic presentation, treatment patterns, nutritional status, outcomes, and comorbidity. Dig Dis Sci. 2012;57:2408-15.

54. Nuij VJ, Zelinkova Z, Rijk MC, et al. Phenotype of inflammatory bowel disease at diagnosis in the Netherlands: a populationbased inception cohort study (the Delta Cohort). Inflamm Bowel Dis. 2013;19:2215-22.

55. Thia KT, Sandborn WJ, Harmsen WS, et al. Risk factors associated with progression to intestinal complications of Crohn's disease in a population-based cohort. Gastroenterology. 2010;139:1147-55.

56. Moum B, Vatn MH, Ekbom A, et al. Incidence of ulcerative colitis and indeterminate colitis in four counties of southeastern Norway, 1990-93. A prospective population-based study. The Inflammatory Bowel South-Eastern Norway (IBSEN) Study Group of Gastroenterologists. Scand J Gastroenterol. 1996;31: 362-6.

57. Ng SC, Tang W, Ching JY, et al. Incidence and phenotype of inflammatory bowel disease based on results from the AsiaPacific Crohn's and colitis epidemiology study. Gastroenterology. 2013;145(1):158.e2-65.e2.

58. Penna C, Dozois R, Tremaine W, et al. Pouchitis after ileal pouch-anal anastomosis for ulcerative colitis occurs with increased frequency in patients with associated primary sclerosing cholangitis. Gut. 1996;38:234-9.

59. Park SJ, Kim WH, Cheon JH. Clinical characteristics and treatment of inflammatory bowel disease: a comparison of Eastern and Western perspectives. World J Gastroenterol. 2014;20:11525-37.

60. Sartor RB. Genetics and environmental interactions shape the intestinal microbiome to promote inflammatory bowel disease versus mucosal homeostasis. Gastroenterology. 2010;139: 1816-9.

61. Gevers D, Kugathasan S, Denson LA, et al. The treatment-naive microbiome in new-onset Crohn's disease. Cell Host Microbe. 2014;15:382-92.

62. Jia H, Lubetkin EI. Trends in quality-adjusted life-years lost contributed by smoking and obesity. Am J Prev Med. 2010;38:138-44.

63. Young VB, Raffals LH, Huse SM, et al. Multiphasic analysis of the temporal development of the distal gut microbiota in patients following ileal pouch anal anastomosis. Microbiome. 2013;1:9.

64. Chan SS, Luben R, Olsen A, et al. Body mass index and the risk for Crohn's disease and ulcerative colitis: data from a European prospective cohort study (the IBD in EPIC study). Am J Gastroenterol. 2013;108:575-82.

65. Mendall MA, Gunasekera AV, John BJ, et al. Is obesity a risk factor for Crohn's disease? Dig Dis Sci. 2011;56:837-44.

66. Khalili H, Ananthakrishnan AN, Konijeti GG, et al. Measures of obesity and risk of Crohn's disease and ulcerative colitis. Inflamm Bowel Dis. 2015;21:361-8.
67. Ferguson A, Sedgwick DM. Juvenile onset inflammatory bowel disease: height and body mass index in adult life. BMJ. 1994;308:1259-63.

68. Kugathasan S, Nebel J, Skelton JA, et al. Body mass index in children with newly diagnosed inflammatory bowel disease: observations from two multicenter North American inception cohorts. J Pediatr. 2007;151:523-7.

69. Ogden CL, Carroll MD, Curtin LR, et al. Prevalence of high body mass index in US children and adolescents, 2007-2008. JAMA. 2010;303:242-9.

70. Blain A, Cattan S, Beaugerie L, et al. Crohn's disease clinical course and severity in obese patients. Clin Nutr. 2002;21:51-7.

71. Renehan AG, Tyson M, Egger M, et al. Body-mass index and incidence of cancer: a systematic review and meta-analysis of prospective observational studies. Lancet. 2008;371:569-78.

72. Harper JW, Sinanan MN, Zisman TL. Increased body mass index is associated with earlier time to loss of response to infliximab in patients with inflammatory bowel disease. Inflamm Bowel Dis. 2013;19:2118-24.

73. Moran CP, Shanahan F. Gut microbiota and obesity: role in aetiology and potential therapeutic target. Best Pract Res Clin Gastroenterol. 2014;28:585-97.

74. Cox LM, Yamanishi S, Sohn J, et al. Altering the intestinal microbiota during a critical developmental window has lasting metabolic consequences. Cell. 2014;158:705-21.

75. Bailey LC, Forrest CB, Zhang P, et al. Association of antibiotics in infancy with early childhood obesity. JAMA Pediatr. 2014;168:1063-9.

76. Shaw SY, Blanchard JF, Bernstein CN. Association between the use of antibiotics in the first year of life and pediatric inflammatory bowel disease. Am J Gastroenterol. 2010;105:2687-92.

77. Greenblum S, Turnbaugh PJ, Borenstein E. Metagenomic systems biology of the human gut microbiome reveals topological shifts associated with obesity and inflammatory bowel disease. Proc Natl Acad Sci U S A. 2012;109:594-9.

78. Liou AP, Paziuk M, Luevano JM, et al. Conserved shifts in the gut microbiota due to gastric bypass reduce host weight and adiposity. Sci Transl Med. 2013;5:178ra141.

79. Kong LC, Tap J, Aron-Wisnewsky J, et al. Gut microbiota after gastric bypass in human obesity: increased richness and associations of bacterial genera with adipose tissue genes. Am J Clin Nutr. 2013;98:16-24.

80. Turnbaugh PJ, Ley RE, Mahowald MA, et al. An obesity-associated gut microbiome with increased capacity for energy harvest. Nature. 2006;444:1027-31.

81. Vrieze A, Van Nood E, Holleman F, et al. Transfer of intestinal microbiota from lean donors increases insulin sensitivity in individuals with metabolic syndrome. Gastroenterology. 2012;143(4):913-16.e7.

82. Kadooka Y, Sato M, Ogawa A, et al. Effect of Lactobacillus gasseri SBT2055 in fermented milk on abdominal adiposity in adults in a randomised controlled trial. Br J Nutr. 2013;110: 1696-703.

83. Kostic AD, Xavier RJ, Gevers D. The microbiome in inflammatory bowel disease: current status and the future ahead. Gastroenterology. 2014;146:1489-99.

84. Darfeuille-Michaud A, Boudeau J, Bulois P, et al. High prevalence of adherent-invasive Escherichia coli associated with ileal mucosa in Crohn's disease. Gastroenterology. 2004;127:412-21.

85. Martinez-Medina M, Aldeguer X, Lopez-Siles M, et al. Molecular diversity of Escherichia coli in the human gut: new ecological evidence supporting the role of adherent-invasive $E$. coli (AIEC) in Crohn's disease. Inflamm Bowel Dis. 2009;15: 872-82.

86. Martinez-Medina M, Garcia-Gil LJ. Escherichia coli in chronic inflammatory bowel diseases: an update on adherent invasive 
Escherichia coli pathogenicity. World J Gastrointest Pathophysiol. 2014;5:213-27.

87. Chassaing B, Rolhion N, de Vallee A, et al. Crohn diseaseassociated adherent-invasive E. coli bacteria target mouse and human Peyer's patches via long polar fimbriae. J Clin Investig. 2011;121:966-75.

88. Morgan XC, Tickle TL, Sokol H, et al. Dysfunction of the intestinal microbiome in inflammatory bowel disease and treatment. Genome Biol. 2012;13:R79.

89. Poltorak A, He X, Smirnova I, et al. Defective LPS signaling in $\mathrm{C} 3 \mathrm{H} / \mathrm{HeJ}$ and $\mathrm{C} 57 \mathrm{BL} / 10 \mathrm{ScCr}$ mice: mutations in Tlr4 gene. Science. 1998;282:2085-8.

90. Franchimont D, Vermeire S, El Housni H, et al. Deficient hostbacteria interactions in inflammatory bowel disease? The toll-like receptor (TLR)-4 Asp299gly polymorphism is associated with Crohn's disease and ulcerative colitis. Gut. 2004;53:987-92.

91. Cario E, Podolsky DK. Differential alteration in intestinal epithelial cell expression of toll-like receptor 3 (TLR3) and TLR4 in inflammatory bowel disease. Infect Immun. 2000;68:7010-7.

92. Benjamin JL, Hedin CR, Koutsoumpas A, et al. Smokers with active Crohn's disease have a clinically relevant dysbiosis of the gastrointestinal microbiota. Inflamm Bowel Dis. 2012;18: 1092-100.

93. Ohkusa T, Sato N, Ogihara T, et al. Fusobacterium varium localized in the colonic mucosa of patients with ulcerative colitis stimulates species-specific antibody. J Gastroenterol Hepatol. 2002; 17:849-53.

94. Kostic AD, Gevers D, Pedamallu CS, et al. Genomic analysis identifies association of Fusobacterium with colorectal carcinoma. Genome Res. 2012;22:292-8.

95. Sears CL, Garrett WS. Microbes, microbiota, and colon cancer. Cell Host Microbe. 2014;15:317-28.

96. Rubinstein MR, Wang X, Liu W, et al. Fusobacterium nucleatum promotes colorectal carcinogenesis by modulating E-cadherin/ $\beta$-catenin signaling via its FadA adhesin. Cell Host Microbe. 2013;14:195-206.

97. Strauss J, Kaplan GG, Beck PL, et al. Invasive potential of gut mucosa-derived Fusobacterium nucleatum positively correlates with IBD status of the host. Inflamm Bowel Dis. 2011;17: 1971-8.

98. Tedelind S, Westberg F, Kjerrulf M, et al. Anti-inflammatory properties of the short-chain fatty acids acetate and propionate: a study with relevance to inflammatory bowel disease. World $\mathbf{J}$ Gastroenterol. 2007;13:2826-32.

99. Ahmad MS, Krishnan S, Ramakrishna BS, et al. Butyrate and glucose metabolism by colonocytes in experimental colitis in mice. Gut. 2000;46:493-9.

100. Smith PM, Howitt MR, Panikov N, et al. The microbial metabolites, short-chain fatty acids, regulate colonic Treg cell homeostasis. Science. 2013;341:569-73.

101. Kang S, Denman SE, Morrison M, et al. Dysbiosis of fecal microbiota in Crohn's disease patients as revealed by a custom phylogenetic microarray. Inflamm Bowel Dis. 2010;16:2034-42.

102. Sokol H, Pigneur B, Watterlot L, et al. Faecalibacterium prausnitzii is an anti-inflammatory commensal bacterium identified by gut microbiota analysis of Crohn disease patients. Proc Natl Acad Sci U S A. 2008;105:16731-6.

103. Flint HJ, Bayer EA, Rincon MT, et al. Polysaccharide utilization by gut bacteria: potential for new insights from genomic analysis. Nat Rev Microbiol. 2008;6:121-31.

104. Duncan SH, Hold GL, Barcenilla A, et al. Roseburia intestinalis sp. nov., a novel saccharolytic, butyrate-producing bacterium from human faeces. Int J Syst Evol Microbiol. 2002;52:1615-20.

105. Sibartie S, Scully P, Keohane J, et al. Mycobacterium avium subsp. paratuberculosis (MAP) as a modifying factor in Crohn's disease. Inflamm Bowel Dis. 2010;16:296-304.
106. Trifan A, Stanciu C, Stoica O, et al. Impact of Clostridium difficile infection on inflammatory bowel disease outcome: a review. World J Gastroenterol. 2014;20:11736-42.

107. Dalmasso M, Hill C, Ross RP. Exploiting gut bacteriophages for human health. Trends Microbiol. 2014;22:399-405.

108. Kernbauer E, Ding Y, Cadwell K. An enteric virus can replace the beneficial function of commensal bacteria. Nature. 2014;516:94-8.

109. Cadwell K, Liu JY, Brown SL, et al. A key role for autophagy and the autophagy gene Atg1611 in mouse and human intestinal Paneth cells. Nature. 2008;456:259-63.

110. Weinbauer MG. Ecology of prokaryotic viruses. FEMS Microbiol Rev. 2004;28:127-81.

111. Rodriguez-Valera F, Martin-Cuadrado AB, Rodriguez-Brito B, et al. Explaining microbial population genomics through phage predation. Nat Rev Microbiol. 2009;7:828-36.

112. Mills S, Shanahan F, Stanton C, et al. Movers and shakers: influence of bacteriophages in shaping the mammalian gut microbiota. Gut Microbes. 2013;4:4-16.

113. Lepage P, Colombet J, Marteau P, et al. Dysbiosis in inflammatory bowel disease: a role for bacteriophages? Gut. 2008;57:424-5.

114. Wagner J, Maksimovic J, Farries G, et al. Bacteriophages in gut samples from pediatric Crohn's disease patients: metagenomic analysis using 454 pyrosequencing. Inflamm Bowel Dis. 2013;19:1598-608.

115. Perez-Brocal V, Garcia-Lopez R, Vazquez-Castellanos JF, et al. Study of the viral and microbial communities associated with Crohn's disease: a metagenomic approach. Clin Transl Gastroenterol. 2013;4:e36.

116. Norman JM, Handley SA, Baldridge MT, et al. Disease-specific alterations in the enteric virome in inflammatory bowel disease. Cell. 2015;160:447-60.

117. Minot S, Sinha R, Chen J, et al. The human gut virome: interindividual variation and dynamic response to diet. Genome Res. 2011;21:1616-25.

118. Modi SR, Lee HH, Spina CS, et al. Antibiotic treatment expands the resistance reservoir and ecological network of the phage metagenome. Nature. 2013;499:219-22.

119. Mukherjee PK, Sendid B, Hoarau G, et al. Mycobiota in gastrointestinal diseases. Nat Rev Gastroenterol Hepatol. 2015;12: 77-87.

120. Dollive S, Peterfreund GL, Sherrill-Mix S, et al. A tool kit for quantifying eukaryotic rRNA gene sequences from human microbiome samples. Genome Biol. 2012;13:R60.

121. Hoffmann C, Dollive S, Grunberg S, et al. Archaea and fungi of the human gut microbiome: correlations with diet and bacterial residents. PLoS One. 2013;8:e66019.

122. Ott SJ, Kuhbacher T, Musfeldt M, et al. Fungi and inflammatory bowel diseases: alterations of composition and diversity. Scand $\mathrm{J}$ Gastroenterol. 2008;43:831-41.

123. Mowat C, Cole A, Windsor A, et al. Guidelines for the management of inflammatory bowel disease in adults. Gut. 2011;60:571-607.

124. Manosa M, Cabre E, Bernal I, et al. Addition of metronidazole to azathioprine for the prevention of postoperative recurrence of Crohn's disease: a randomized, double-blind, placebo-controlled trial. Inflamm Bowel Dis. 2013;19:1889-95.

125. Khan KJ, Ullman TA, Ford AC, et al. Antibiotic therapy in inflammatory bowel disease: a systematic review and metaanalysis. Am J Gastroenterol. 2011;106:661-73.

126. Shanahan F, Quigley EM. Manipulation of the microbiota for treatment of IBS and IBD-challenges and controversies. Gastroenterology. 2014;146:1554-63.

127. van Nood E, Dijkgraaf MG, Keller JJ. Duodenal infusion of feces for recurrent Clostridium difficile. $N$ Engl $\mathrm{J}$ Med. 2013;368:2145. 
128. Anderson JL, Edney RJ, Whelan K. Systematic review: faecal microbiota transplantation in the management of inflammatory bowel disease. Aliment Pharmacol Ther. 2012;36:503-16.

129. Kunde S, Pham A, Bonczyk S, et al. Safety, tolerability, and clinical response after fecal transplantation in children and young adults with ulcerative colitis. J Pediatr Gastroenterol Nutr. 2013;56:597-601.

130. Angelberger S, Reinisch W, Makristathis A, et al. Temporal bacterial community dynamics vary among ulcerative colitis patients after fecal microbiota transplantation. Am J Gastroenterol. 2013;108:1620-30.
131. Gough E, Shaikh H, Manges AR. Systematic review of intestinal microbiota transplantation (fecal bacteriotherapy) for recurrent Clostridium difficile infection. Clin Infect Dis. 2011;53: 994-1002.

132. Petrof EO, Khoruts A. From stool transplants to next-generation microbiota therapeutics. Gastroenterology. 2014;146:1573-82.

133. Petrof EO, Gloor GB, Vanner SJ, et al. Stool substitute transplant therapy for the eradication of Clostridium difficile infection: 'RePOOPulating' the gut. Microbiome. 2013;1:3. 